\title{
Association of high serum vitamin D concentrations with active pulmonary TB in an HIV co-endemic setting, Harare, Zimbabwe
}

Cuthbert Musarurwa ${ }^{{ }^{*}}$ DD, Lynn Sodai Zijenah², Doreen Zvipo Duri ${ }^{1}$, Kudzie Mateveke-Dangaiso ${ }^{3}$, Kudakwashe Mhandire ${ }^{1}$, Maria Mary Chipiti ${ }^{2}$, Marshall Wesley Munjoma ${ }^{4}$ and Witmore Bayayi Mujaji ${ }^{1}$

\begin{abstract}
Background: There is paucity data on the association of vitamin D deficiency (VDD) and active tuberculosis (TB) in southern Africa where the human immunodeficiency virus (HIV) is co-endemic. We examined the association of serum vitamin D concentrations with active pulmonary tuberculosis (PTB) in HIV-infected $(n=284)$ and uninfected ( $n=267)$ Black Zimbabweans, in Harare, Zimbabwe.

Methods: We conducted a cross-sectional study of 551 participants comprising $145 \mathrm{HIV}^{+} / \mathrm{PTB}^{+}, 139 \mathrm{HIV}^{+} / \mathrm{PTB}^{-}, 134$ $\mathrm{HIV}^{-} / \mathrm{PTB}^{+}$and $133 \mathrm{HIV}^{-} / \mathrm{PTB}^{-}$. PTB status was confirmed using sputum by culture, or smear microscopy, or GeneXpert MTB/RIF. Serum 25-hydroxyvitamin D (25(OH)D) concentrations were measured using a competitive chemiluminescent immunoassay prior to commencement of anti-TB treatment.

Results: In all four groups, the median vitamin D concentrations were above the $20 \mathrm{ng} / \mathrm{ml}$ cut off for VDD. However, the median vitamin $D$ concentrations in all the four groups were below the cut off for vitamin $D$ sufficiency $\geq 30 \mathrm{ng} / \mathrm{ml}$. The median vitamin D concentrations were significantly higher in PTB cases; $24.2 \mathrm{ng} / \mathrm{ml}$ (IQR: 18.8-32.0) compared to PTB ${ }^{-}$controls $20.9 \mathrm{ng} / \mathrm{ml}$ (IQR: 17.1-26.9), $p<0.0001$ regardless of HIV status. The HIV ${ }^{+} / \mathrm{PTB}^{+}$group had the highest median vitamin D concentration (25.3 (IQR: 18.0-33.7 ng/ml) whilst the $\mathrm{HIV}^{+} / \mathrm{PTB}^{-}$ group had the lowest; $20.4 \mathrm{ng} / \mathrm{ml}$ (IQR: $14.6-26.9), p=0.0003$. Vitamin D concentration $<30 \mathrm{ng} / \mathrm{ml}$ was associated with $43 \%$ lower odds of being PTB ${ }^{+}$OR 0.57 (95\% Cl 0.35-0.89).

Conclusions: Our results are not in agreement with the generally accepted hypothesis that VDD is associated with active PTB. To the contrary our results showed an association of higher vitamin D concentrations with active TB irrespective of HIV status. Although findings from the available pool of case control studies remain inconsistent, the results from the current study provide further rationale for larger-scale, prospectively designed studies to evaluate whether sufficient vitamin D concentrations do indeed precede the development of active PTB in our setting.
\end{abstract}

Keywords: Vitamin D deficiency, Pulmonary tuberculosis, HIV status, Harare, Zimbabwe

\footnotetext{
* Correspondence: curtbertm@yahoo.com

${ }^{1}$ Department of Chemical Pathology, University of Zimbabwe, College of

Health Sciences, P.O. Box A178, Avondale, Harare, Zimbabwe

Full list of author information is available at the end of the article
} 


\section{Background}

Zimbabwe, a country ranked $17^{\text {th }}$ out of 22 high burden countries that together contribute $80 \%$ of the global tuberculosis (TB) burden, had a TB prevalence of 409/100 000 in 2013 [1]. The resurgence of the TB epidemic in Zimbabwe is fuelled by HIV with $\sim 80 \%$ co infection rates [1].

Susceptibility to TB is associated with host immune response which in turn may be influenced by environmental and genetic factors or interactions between the two [2, 3]. Vitamin D, an immunomodulatory effector via the vitamin $\mathrm{D}$ receptor, has been reported to be critical in inducing antimycobacterial activity by inhibiting the growth of Mycobacterium tuberculosis (MTB) and up-regulating innate host responses [4-6]. Evidence of this was derived from in vitro studies which demonstrated that vitamin $\mathrm{D}$ metabolites regulate the expression of cathelicidin (LL-37), an endogenous antimycobacterial peptide in cultured macrophages [7-10].

There is paucity of data on association of serum vitamin $\mathrm{D}$ concentrations with $\mathrm{TB}$ in southern Africa where HIV is co-endemic. We thus conducted a cross-sectional study to measure the concentrations of serum vitamin $\mathrm{D}$ and to examine their association with active pulmonary TB (PTB) in HIV-infected and uninfected Black Zimbabweans in Harare, Zimbabwe.

\section{Methods}

\section{Study setting and design}

Harare is located at latitude $17^{\circ} 55^{\prime} \mathrm{S}$ and longitude $31^{\circ} 7^{\prime} \mathrm{E}$ and at an altitude of $1480 \mathrm{~m}$. The study participants were all dark skinned and unveiled, with faces and arms regularly exposed to the sun.

We used stratified sampling to enrol consecutive consenting participants into four participant groups: HIV/TB co-infected $\left(\mathrm{HIV}^{+} / \mathrm{PTB}^{+}\right), \mathrm{HIV}$ infected/PTB negative $\left(\mathrm{HIV}^{+} / \mathrm{PTB}^{-}\right), \mathrm{HIV}$ uninfected/PTB positive $\left(\mathrm{HIV}^{-} / \mathrm{PTB}^{+}\right)$ and $\mathrm{HIV} / \mathrm{TB}$ uninfected $\left(\mathrm{HIV}^{-} / \mathrm{PTB}^{-}\right)$. HIV infected participants were under routine care as specified by prevailing national guidelines whereas $\mathrm{PTB}^{+}$participants were TB treatment naïve prior to measurement of serum vitamin D concentrations.

\section{Study participants}

$\mathrm{HIV}^{-}$participants aged $>18$ years were recruited from City of Harare Clinics. $\mathrm{HIV}^{-} / \mathrm{PTB}{ }^{-}$participants were healthcare workers and attendees at the institutional voluntary HIV testing and counseling centres with documented HIV and PTB negative status (Fig. 1). Similarly, $\mathrm{HIV}^{-} / \mathrm{PTB}^{+}$enrolled at the same centres had documented HIV and PTB status. PTB infection was confirmed on sputum by culture, smear microscopy or by Xpert MTB/RIF ${ }^{\circ}$ (Cepheid Sunnyvale, United States). At enrolment, sociodemographic characteristics and clinical variables were assessed and recorded by completion of a questionnaire for all consenting participants. Thereafter, $5 \mathrm{mls}$ venous blood was collected by venipuncture from which serum was harvested by centrifugation at $3000 \mathrm{rpm}$ for $5 \mathrm{~min}$ and stored at $-80{ }^{\circ} \mathrm{C}$ until subsequent measurements of vitamin $\mathrm{D}$ concentrations.

Stored serum specimens for the $\mathrm{HIV}^{+} / \mathrm{PTB}^{+}$and $\mathrm{HIV}$ ${ }^{+} / \mathrm{PTB}^{-}$groups were obtained from participants who were enrolled in a randomised controlled trial (RCT) entitled 'A randomized controlled trial to evaluate the impact of using a point-of-care urine lipoarabinomannan (LAM) strip test for TB diagnosis amongst hospitalized HIV-infected patients in resource-poor settings (RCT LAM)'. The RCT LAM was enrolling patients at the same period as recruitment was taking place from the city of Harare clinics, the institutional voluntary HIV testing and counseling centres in Harare. Details of the RCT are described elsewhere [11, 12]. Appropriate demographic and laboratory data for these two groups of participants were abstracted from the RCT LAM database. All such data and specimens were anonymized before access was allowed to the current investigators.

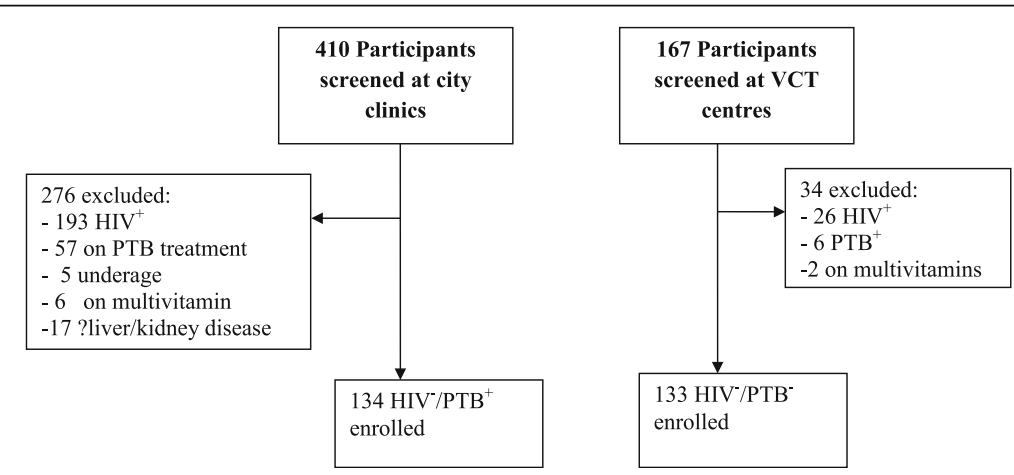

Fig. 1 Participants Enrolment Chart. HIV = Human immunodeficiency virus; $\mathrm{HIV}^{+}=\mathrm{HIV}$ positive; $\mathrm{HIV}^{-}=\mathrm{HIV}$ negative; PTB = Pulmonary tuberculosis; $\mathrm{PTB}^{+}=$PTB positive; $\mathrm{PTB}^{-}=$PTB negative 


\section{Case definition}

PTB cases either HIV-infected or - uninfected, were sputum smear microscopy or culture (using mycobacterial growth indicator tube) or GeneXpert MTB/RIF positive.

\section{Control definition}

Controls were PTB culture negative and either HIVinfected or uninfected.

\section{Bacteriological testing}

At enrolment, at least three sputum specimens were collected from each participant for same day testing (MTB/ RIF, or microscopy). One sputum specimen was submitted for culture.

Sputum smear microscopy using a fluorescence microscope was done with auramine stain for screening and confirmation of auramine positive smear was with ZiehlNeelsen (Z-N) stain.

The Xpert MBT/RIF assay was performed as previously described [13]. Briefly, the sample reagent was added in a volume twice that of the untreated sputum and incubated for $15 \mathrm{~min}$. Two millimetres of the processed sputum was then transferred to the MTB/RIF assay catridge and then inserted into the Gene Xpert instrument.

The Mycobacteria Growth Indicator Tube (MGIT BD Microbiology Systems, Cockeysville, MD, USA) culture was performed on sputum decontaminated using $4 \% \mathrm{NaOH}$. Suspected positive cultures were confirmed using Z-N staining. MPT64 antigen detection was used for speciation of MGIT positive cultures and by growth at different temperatures if antigen detection was negative [14].

\section{Vitamin D assays}

Serum 25(OH)D was measured as a marker of vitamin D status using a fully automated competitive chemiluminescent immunoassay analyser (Maglumi 2000 Snibe Co. Ltd Shenzhen, 518057 China). The assay was carried out in accordance with the manufacturer's instructions. Serum specimens were thawed only once for the analysis cycle. Between-run precision coefficients of variation for the assay ranged from 6.04 to $6.25 \%$ and within run precision coefficients of variation ranged from 3.01 to $3.45 \%$.

Serum $25(\mathrm{OH}) \mathrm{D}$ concentrations are generally accepted as being reflective of the overall vitamin $\mathrm{D}$ status because of a longer half-life of approximately 15 days compared to $15 \mathrm{~h}$ for the active form $[15,16]$. Thus in this write up, serum vitamin D concentration is used synonymously with serum $25(\mathrm{OH}) \mathrm{D}$ concentration. Vitamin $D$ deficiency (VDD) was defined as serum 25(OH)D concentration $<20 \mathrm{ng} / \mathrm{mL}$, vitamin $\mathrm{D}$ insufficiency as serum $25(\mathrm{OH}) \mathrm{D}$ concentration $\geq 20-29 \mathrm{ng} / \mathrm{mL}$, and sufficient vitamin D status as serum $25(\mathrm{OH}) \mathrm{D} \geq 30 \mathrm{ng} /$ $\mathrm{ml}[17,18]$. Vitamin D concentrations below $10 \mathrm{ng} / \mathrm{ml}$ were classified as severely vitamin D deficient [19].

\section{Ethics statement}

The study protocol was approved by the Medical Research Council of Zimbabwe (MRCZ/A/1906). All the participants enrolled from the Harare City Clinics gave their written informed consent to participate in the study. All the participants from the RCT LAM consented to use of their leftover archived specimens and data in future TB related studies.

\section{Statistical analyses}

All statistical analyses were conducted using the STATA statistical software package (version 13.0; Stata Corporation, College Station, Texas, USA) and GraphPad Prism (version 5; GraphPad Prism Inc, San Diego, CA, USA). Data were summarised by count and proportion (\%) and median and interquartile range (IQR) for non-normally distributed variables or means \pm standard deviations for normally distributed data. Chi-square test was used to test for differences in proportions. Differences between groups of continuous normally distributed data were tested using independent samples $t$-test and ANOVA whilst the non-parametric Mann-Whitney or Kruskal Wallis tests were used respectively for non-normal data. Dunn's test for multiple cross group rank sum comparisons was used to compare median vitamin D levels by HIV/PTB status. For all statistical comparisons $\alpha$ was set at 0.05. Co-variates of VDD were determined using logistic regression as was the effect of vitamin $\mathrm{D}$ status on PTB status. Logistic regression was also used to determine the association between PTB and vitamin D deficiency, insufficiency, optimal and severe vitamin D deficiency. Odds ratios and their 95\% confidence intervals were reported for all such cases.

\section{Results \\ Study population}

The clinico-demographic data of the 551 study participants stratified into four groups $\mathrm{HIV}^{+} / \mathrm{PTB}^{+} \quad(n=$ 145), $\mathrm{HIV}^{+} / \mathrm{PTB}^{-}(n=139), \mathrm{HIV}^{-} / \mathrm{PTB}^{+}(n=134)$ and $\mathrm{HIV}^{-} / \mathrm{PTB}^{-}(n=133)$ are presented in Table 1.

The mean age of the study participants was 38.5 years (SD12.3). Participants in the $\mathrm{HIV}^{-} / \mathrm{PTB}^{-}$group were statistically significantly younger than those in the $\mathrm{HIV}^{+} / \mathrm{TB}^{-}$ group; $p=0.002$ and the $\mathrm{HIV}^{-} / \mathrm{TB}^{+}$group $p=0.016$ (Table 1). The proportion of males in the $\mathrm{HIV}^{-} / \mathrm{TB}^{+}(64 \%)$ was significantly higher that of the $\mathrm{HIV}^{-} / \mathrm{TB}^{-}$group (42\%), $p=0.0003$.

The vitamin D concentrations and status of the four study groups are shown in Table 2. 
Table 1 Participant demographics

\begin{tabular}{|c|c|c|c|c|c|c|}
\hline Variable & $\begin{array}{l}\text { All } \\
n=551\end{array}$ & $\begin{array}{l}\mathrm{HIV}^{+} / \mathrm{PTB}^{+} \\
n=145\end{array}$ & $\begin{array}{l}\mathrm{HIV}^{+} / \mathrm{PTB}^{-} \\
n=139\end{array}$ & $\begin{array}{l}\mathrm{HIV}^{-} / \mathrm{PTB}^{+} \\
n=134\end{array}$ & $\begin{array}{l}\mathrm{HIV}^{-} / \mathrm{PTB}^{-} \\
n=133\end{array}$ & $p$ value \\
\hline Age in years; mean(SD) & $38.5(12.3)$ & $38.6(9.0)$ & $40.5(12.6)$ & $39.7(16.5)$ & $35.1(8.9)$ & \multirow{2}{*}{$\begin{array}{l}0.0017 \\
*\end{array}$} \\
\hline Males n (\%) & $272(51)$ & $63(48)$ & $70(50)$ & $84(64)$ & $55(42)$ & \\
\hline
\end{tabular}

"Significant difference between $\mathrm{HIV}^{+} / \mathrm{PTB}^{-}$and $\mathrm{HIV}^{-} / \mathrm{PTB}^{+} p=0.02$ and significant difference $\mathrm{HIV}^{-} / \mathrm{PTB}^{+}$and $\mathrm{HIV}^{-} / \mathrm{PTB}^{-}$

The overall median serum vitamin $\mathrm{D}$ concentration was $22.5 \mathrm{ng} / \mathrm{ml}$ (IQR 17.7-29.3) (Table 2). Median serum vitamin $\mathrm{D}$ concentrations were statistically significantly different by HIV/PTB infection status; $p=0.0001$. The $\mathrm{HIV}^{+} / \mathrm{PTB}^{+}$group had the highest median serum vitamin D concentration $25.3 \mathrm{ng} / \mathrm{ml}$ (IQR 18.0-33.7) whilst the $\mathrm{HIV}^{+} / \mathrm{PTB}^{-}$group the lowest 20.4 (IQR14.626.9) $\mathrm{ng} / \mathrm{ml}$. The median serum vitamin $D$ concentration was statistically significantly higher for the $\mathrm{HIV}^{+} / \mathrm{PTB}^{+}$ group versus the $\mathrm{HIV}^{+} / \mathrm{PTB}^{-}$group $(p<0.0001)$ and the $\mathrm{HIV}^{-} / \mathrm{PTB}^{-}$group $(p=0.008)$. The median serum vitamin $\mathrm{D}$ concentration was also statistically significant higher for the $\mathrm{HIV}^{-} / \mathrm{PTB}^{+}$group versus the $\mathrm{HIV}^{-} / \mathrm{PTB}^{-}$ $(p=0.02)$ and the $\mathrm{HIV}^{+} / \mathrm{PTB}^{-}$group $(p=<0.001)$. However there were no statistically significant differences in median vitamin D concentrations between the HIV ${ }^{+} / \mathrm{PTB}^{+}$and $\mathrm{HIV}^{-} / \mathrm{PTB}^{+}$groups $p=0.41$ and between the $\mathrm{HIV}^{+} \mathrm{PTB}^{-}$and $\mathrm{HIV}^{-} / \mathrm{PTB}^{-}$groups $p=0.06$. None of the four study groups had median vitamin D concentrations above the optimum cut off point of $30 \mathrm{ng} / \mathrm{ml}$ (Fig. 2).

The proportions of individuals in each of the vitamin D status strata were significantly different across the 4 HIV/PTB participant groups $(p<0.001)$. (Table 2) The $\mathrm{HIV}^{+} / \mathrm{PTB}^{-}$group had the highest proportion $(48 \%)$ of vitamin $\mathrm{D}$ deficient participants whilst the $\mathrm{HIV}^{-} / \mathrm{PTB}^{+}$ group had the lowest proportion (28\%); $p=0.0008$. The $\mathrm{HIV}^{+} / \mathrm{PTB}^{+}$group had the highest proportion $(35 \%)$ of individuals with sufficient vitamin $\mathrm{D}$ concentration $(\geq 30 \mathrm{ng} / \mathrm{ml})$ whilst the $\mathrm{HIV}^{-} / \mathrm{PTB}^{-}$had the lowest proportion (12\%); $p<0.0001$.

\section{Correlates of serum vitamin D levels}

The association between serum vitamin D status was further analysed by comparing the median serum vitamin D concentrations by age, gender, HIV and PTB status (Table 3). Univariate logistic regression was conducted to ascertain determinants of serum vitamin D status. All univariate logistic regression factors with a $p$-value that was less than 0.25 were included in the multiple logistic regression model.

Disregarding the HIV status, $\mathrm{PTB}^{+}$participants had statistically significantly higher median serum vitamin $\mathrm{D}$ concentration compared to $\mathrm{PTB}^{-}$participants $(p<$ $0.0001)$. Median serum vitamin D concentrations were also statistically significantly higher in females compared to males $(p=0.017)$ but did not differ significantly by HIV status or age $>50$ years. Gender was not a significant correlate of vitamin D status in both univariate and multivariate logistic analysis but age $>50$ years in multivariate analysis was a predictor of vitamin $\mathrm{D}$ deficiency with adjusted OR 1.05 (95\%CI 1.01-1.1). Participants with vitamin D concentrations $<30 \mathrm{ng} / \mathrm{ml}$ were $43 \%$ less likely to be $\mathrm{PTB}^{+}$; OR 0.57 (95\% CI $0.35-0.89$ ) and $62 \%$ less likely to be $\mathrm{HIV}^{+}$compared to those with sufficient vitamin D concentrations. VDD OR 0.75 (95\%CI $0.51-$ 1.10) and severe VDD OR 0.26 (95\%CI $0.03-2.29)$ were not associated with PTB positivity.

\section{Discussion}

Our study has some intriguing findings. Firstly, in our study population the prevalence of vitamin D deficiency was $37 \%$. Secondly, the median serum vitamin D concentration in all the four groups was above the cut off level defining VDD $(<20 \mathrm{ng} / \mathrm{ml})$, ironically with highest medians being in the $\mathrm{PTB}^{+}$groups regardless of HIV status compared to the $\mathrm{PTB}^{-}$groups. Thirdly, and paradoxically, the $\mathrm{PTB}^{+}$groups irrespective of HIV status had the lowest proportions of participants with serum VDD when compared to the $\mathrm{PTB}^{-}$groups. Fourthly, and

Table 2 Vitamin D concentrations status stratified by HIV/TB status

\begin{tabular}{|c|c|c|c|c|c|}
\hline & $\begin{array}{l}\text { All } \\
n=551\end{array}$ & $\begin{array}{l}\mathrm{HIV}^{+} / \mathrm{PTB}^{+} \\
n=145\end{array}$ & $\begin{array}{l}\mathrm{HIV}^{+} / \mathrm{PTB}^{-} \\
n=139\end{array}$ & $\begin{array}{l}\mathrm{HIV}^{-} / \mathrm{PTB}^{+} \\
n=134\end{array}$ & $\begin{array}{l}\mathrm{HIV}^{-} / \mathrm{PTB}^{-} \\
n=133\end{array}$ \\
\hline Vitamin D ng/ml median (IQR) & $22.5(17.7-29.3)$ & $25.3(18.0-33.7)$ & $20.4(14.6-26.9)$ & $24.0(19.5-29.6)$ & $21.6(18.3-26.5)$ \\
\hline \multicolumn{6}{|l|}{ Vitamin D status } \\
\hline Vitamin D deficient (n\%) $(<20$ ng/ml) & 205(37.2) & 49(33.8) & $67(48.2)$ & $38(28.4)$ & $51(38.4)$ \\
\hline Severe vitamin D deficiency $(\mathrm{n} \%)(<10 \mathrm{ng} / \mathrm{ml})$ & $6(1.1)^{\mathrm{a}}$ & 0 & $5(3.6)^{a}$ & $1(0.8)^{a}$ & 0 \\
\hline Vitamin D insufficient (n\%) $(\geq 20<30 \mathrm{ng} / \mathrm{ml})$ & 218(39.6) & $46(31.7)$ & $42(30.2)$ & $64(47.9)$ & $66(49.6)$ \\
\hline Vitamin D sufficient $(\mathrm{n} \%)(\geq 30 \mathrm{ng} / \mathrm{ml})$ & 128(23.2) & $50(34.5)$ & $30(21.6)$ & $32(23.9)$ & 16(12.0) \\
\hline
\end{tabular}

${ }^{a}$ Severe vitamin $D$ deficient participants also included in vitamin $D$ deficient participant frequency 


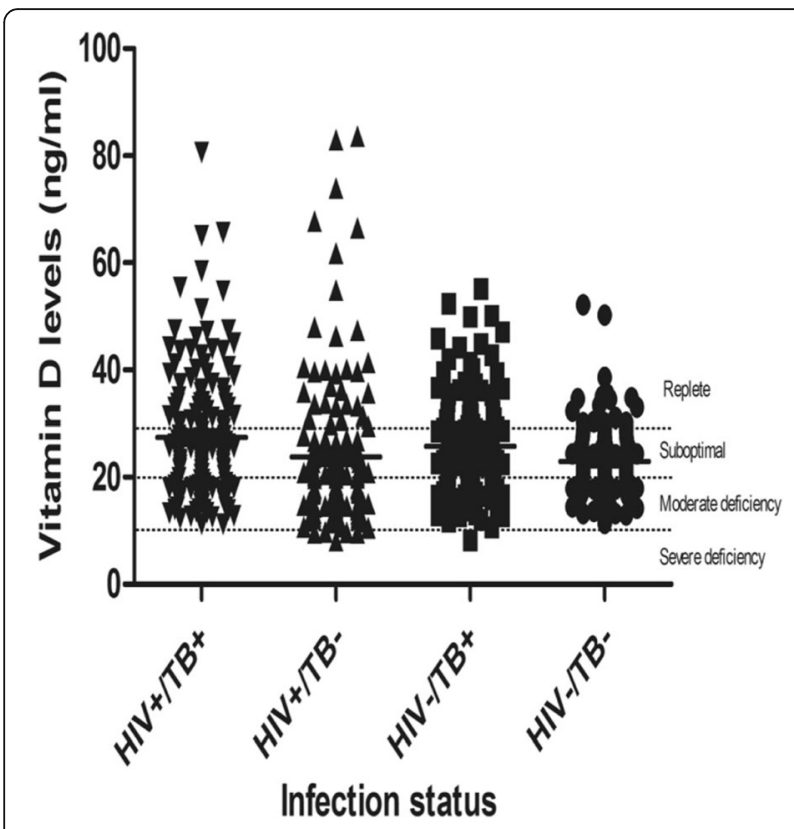

Fig. 2 Serum vitamin D concentrations in $\mathrm{HIV}^{+} / \mathrm{PTB}^{+}(n=145), \mathrm{HIV}$ ${ }^{+} / \mathrm{PTB}^{-}(n=139), \mathrm{HIV}^{-} / \mathrm{TB}^{+}(n=134)$, and HIV/PTB ${ }^{-}(n=133)$. Serum vitamin D: 25-hydroxyvitamin D; TB: Pulmonary Tuberculosis; HIV = human immunodeficiency virus; +: Positive; -: Negative. The solid horizontal lines ( ${ }^{\prime}$ indicate the median vitamin D level for each. The broken horizontal lines (.....) demarcate the cutoff points for each vitamin D status category

conversely, the $\mathrm{PTB}^{+}$groups had the highest proportions of participants with sufficient $(\geq 30 \mathrm{ng} / \mathrm{ml}$ ) vitamin D concentrations compared to the $\mathrm{PTB}^{-}$controls, implying that active PTB is associated with relatively, higher concentrations of vitamin D. In support of this is the observation that the double negative control group, $\left(\mathrm{HIV}^{-} / \mathrm{TB}^{-}\right)$had

Table 3 Co-variates of serum vitamin D status

\begin{tabular}{|c|c|c|c|}
\hline Variable & $\begin{array}{l}\text { Serum Vitamin D } \\
\mathrm{ng} / \mathrm{ml} \text { Median(IQR) }\end{array}$ & $p$-value & $\begin{array}{l}\text { Odds ratio } \\
95 \% \mathrm{Cl}\end{array}$ \\
\hline \multicolumn{4}{|l|}{ Gender $n=533$} \\
\hline 1. Male $n=272$ & $21.98(16.4-28.5)$ & 0.017 & Referent \\
\hline 2. Female & $22.83(18.5-29.9)$ & & $0.8(0.5-1.2)$ \\
\hline \multicolumn{4}{|l|}{ Age $n=550$} \\
\hline 1. $\leq 50$ years $n=452$ & $22.63(17.7-29.4)$ & 0.409 & Referent \\
\hline 2. $>50$ years & 22.05 (17.6-28.8) & & $0.8(0.5-1.3)$ \\
\hline \multicolumn{4}{|l|}{ TB status $n=550$} \\
\hline 1. PTB positive $n=279$ & $24.21(18.8-32.0)$ & $<0.001$ & $0.57\left(0.35-0.89^{a}\right.$ \\
\hline 2. PTB negative & $20.91(17.1-26.9)$ & & \\
\hline \multicolumn{4}{|l|}{ HIV status $n=550$} \\
\hline Infected $n=283$ & $22.14(16.4-31.5)$ & 0.394 & $0.38(0.24-0.60)^{a}$ \\
\hline Uninfected & $22.63(18.9-28.4)$ & & \\
\hline
\end{tabular}

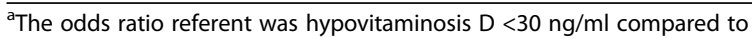
optimal vitamin D concentration $>30 \mathrm{ng} / \mathrm{ml}$

${ }^{\mathrm{b}}$ Referent was serum vitamin $\mathrm{D}<20 \mathrm{ng} / \mathrm{ml}$ the highest proportion of participants with insufficient serum vitamin D concentrations. Fifthly and similarly, this group had the lowest proportion of participants with sufficient vitamin $\mathrm{D}$ concentrations. Indeed in a multivariate analysis insufficient concentrations of vitamin $\mathrm{D}$ were associated with a lower risk of being $\mathrm{PTB}^{+}$. Sixthly, age $>50$ years was a predictor of vitamin D deficiency.

VDD has been associated with increased risk of several infectious and metabolic diseases [3, 20, 21]. In vitro studies further indicate that physiological concentrations of 1,25 dihyroxycholecalciferol (1,25D3) inhibit both HIV and $M$. tuberculosis replication in human macrophages via an autophagy and cathelicidin dependent mechanism [10]. The in-vivo association between vitamin $\mathrm{D}$ status and tuberculosis however remains contentious [16, 22-24].

To our knowledge, only three other studies in sub Saharan Africa have examined the association of vitamin D status with TB in a HIV endemic setting [16, 22, 25]. Our observations of higher median vitamin D concentrations, lower proportions of participants with vitamin $\mathrm{D}$ deficiency and insufficiency in the $\mathrm{PTB}^{+} / \mathrm{HIV}^{+}$groups regardless of HIV status are similar to those reported in a cross-sectional study conducted in Tanzania [25]. In sharp contrast to our results, the observational study in Cape Town, South Africa, with four groups of study participants similar to our study (although their study distinguished latent from active $\mathrm{TB})$, reported a high prevalence $(62.7 \%)$ of VDD $(<20 \mathrm{ng} / \mathrm{ml})$ in all the four groups [22]. Active TB was associated with VDD in both HIV-infected and uninfected participants with the association being stronger in the former group. Optimal/sufficient ( $>30 \mathrm{ng} / \mathrm{ml}$ ) serum vitamin D concentrations were associated with active TB in HIVinfected but not in the HIV-uninfected participants. The study also reported a reciprocal seasonal variation in vitamin $\mathrm{D}$ status and tuberculosis notifications. We did not investigate this aspect in Zimbabwe and we do not know if the seasonal variation may partially explain the differences in the results from our study. A prospective observational study with similar study participants groups to ours (but a smaller cohort), conducted in Uganda, reported low prevalence of VDD with more than $50 \%$ of the participants having optimal vitamin D concentrations in all the four groups [16]. There were no significant differences in vitamin $\mathrm{D}$ status or the median vitamin $\mathrm{D}$ concentrations in the four groups. The observed differences between the two studies could be explained by the proximity of Uganda to the equator and the likely differences in the solar zenith angle that would enable an individual close to the equator to synthesize vitamin D more efficiently [26]. 
Although our findings are discordant with the generally accepted hypothesis that VDD is associated with PTB [22, 23], they are biologically plausible. PTB infection infamously known as 'the consumption' [27] in the past, could lead to higher vitamin D levels by two mechanisms. Adipose tissue is a reservoir of vitamin D [28] and wasting associated with PTB could result in increased release of sequestered vitamin $\mathrm{D}$ into circulation. Higher vitamin levels reported by others, in participants with body mass index (BMI) $\leq 18.5$ compared to those of higher BMI lend further support to our speculation $[22,25]$. On the other hand, MTB induces expression of 1- $\alpha$-hydroxylase (CYP27B1) in macrophages thus mediating local conversion of $25(\mathrm{OH}) \mathrm{D}$ to $1,25 \mathrm{D} 3$. This induction enhances the ability of macrophages to restrict mycobacterial growth $[6,10]$. Heightened immune activation in $\mathrm{HIV}^{+} / \mathrm{PTB}^{+}$participants might therefore lead to increased consumption of $25(\mathrm{OH}) \mathrm{D}$ and its further mobilisation from adipose tissue into circulation.

Several other studies to examine vitamin D status and association with PTB have been conducted globally albeit with conflicting results. In general, studies performed in African [19, 22, 29, 30] and Caucasian populations [31] have reported lower vitamin D concentrations in TB patients than in controls while the results from Asia are variable. There were no significant differences in median vitamin $\mathrm{D}$ concentrations between $\mathrm{TB}$ cases and controls in Indonesia [32] China [33], South Korea [34] and Afghanistan [35]. In contrast, in a recent study conducted in Vietnam, vitamin $D$ insufficiency was more prevalent in males with TB than in controls [36].

The geographical variation of vitamin D status and association with TB may be attributable to differences in cultural behaviours, exposure to sunshine, dietary intake of vitamin D, and genetic factors. A study of Asians in London reported that genetic polymorphisms in the vitamin $\mathrm{D}$ receptor gene can result in differing susceptibility to VDD [23].

The conflicting results on the association of vitamin $\mathrm{D}$ deficiency with an increased risk of PTB may also be attributable to the differing criteria for VDD. In some studies, a concentration of $25-(\mathrm{OH}) \mathrm{D} 3<20 \mathrm{ng} / \mathrm{ml}$ was used as a cut off $[19,22,23]$, while other studies used a concentration of $25-(\mathrm{OH}) \mathrm{D} 3$ of $<25 \mathrm{nmol} / \mathrm{L}[34,36]$. Some studies used other criteria such as $25-50 \mathrm{nmol} / \mathrm{L}$ [16]. The criteria for other commonly used terminologies such as vitamin D insufficiency, severe insufficiency and sufficient and their association with $\mathrm{TB}$ also vary across the studies $[16,19,22,23,35]$ We selected the vitamin D deficiency, insufficiency and sufficiency thresholds as widely recommended in other studies $[17,18]$. Mao et al. raise a point of caution on the possibility that the cut off points as suggested by the Institute of Medicine, which are based on skeletal health for a predominantly Caucasian population, may not be ideal for other races in other settings [37]. It might therefore be prudent to establish local reference intervals for different settings and racial groups.

\section{Limitations}

A major limitation of the current analysis is the crosssectional design which precludes causal inferences to be made on the observed associations due to lack of temporality and the possibility of reverse causality. The unmatched nature of the comparison groups in this crosssectional design probably also impedes drawing of stronger conclusions. Other limitations include lack of data on sunshine exposure and dietary habits. Despite these, the study had a major advantage of a fairly large sample size and also included $\mathrm{HIV}^{+}$and $\mathrm{HIV}^{-}$comparison groups unlike some similarly designed studies that were underpowered or did not include $\mathrm{PTB}^{-}$comparison groups.

\section{Conclusions}

In our study vitamin D concentration $<30 / \mathrm{ng} / \mathrm{ml}$, were associated with lower odds of being $\mathrm{PTB}^{+}$. Paradoxically, the $\mathrm{PTB}^{+}$groups regardless of HIV status not only had the highest median serum vitamin D concentrations but also the highest proportion of participants with sufficient vitamin $\mathrm{D}$ concentration $(\geq 30 \mathrm{ng} / \mathrm{ml})$ implying that higher median and optimal vitamin D concentrations are associated with active $\mathrm{PTB}$. We recommend prospective studies to evaluate whether sufficient vitamin D concentrations precede the development of active PTB.

\section{Abbreviations}

25(OH)D: 25-hydroxyvitamin D; ANOVA: Analysis of variance; BMI: Body mass index; HIV: Human immunodeficiency virus; IQR: Interquartile range;

LAM: Lipoarabinomannan; MRCZ: Medical research council of Zimbabwe; MTB: Mycobacterium tuberculosis; OR: Odds ratio; PTB: Pulmonary tuberculosis; RCT: Randomised controlled trial; SD: Standard deviation; TB: Tuberculosis; VDD: Vitamin D deficiency; Xpert MTB RIF: GeneXpert Mycobacteria tuberculosis Rifampicin

\section{Acknowledgements \\ Not applicable.}

\section{Funding}

The authors gratefully acknowledge funding from the European and Developing Countries Trials Partnership (IP.0932040009), Southern Africa Consortium for Research Excellence and grant number 2U2RTW007367 from the Fogarty International Centre, National Institutes of Health, USA through the International Clinical, Operations, and Health Services Research Training Award for AIDS and TB. The funders played no role in the design of the study and collection, analysis, and interpretation of data and in writing the manuscript.

\section{Availability of data and materials}

The datasets used during and/or analysed during the current study available from the corresponding author on reasonable request. 


\section{Authors' contributions}

CM, LSZ, WBM and MWM conceived the study and its design. CM, MMC and DZD participated in the collection of clinical material and study participant recruitment. CM, DZD and KM conducted laboratory tests. KMD and CM performed data analysis. CM wrote the first draft with input from LSZ, WBM, MWM, DZD, KM, KMD and MMC. All authors reviewed and approved the final version of the manuscript.

\section{Competing interests}

The authors declare that they have no competing interests.

\section{Consent for publication}

Not Applicable.

\section{Ethics approval and consent to participate}

The study protocol was approved by the Medical Research Council of Zimbabwe (MRCZ/A/1906). All participants gave written informed consent whilst all participants with archived specimens consented to future use in TB related studies.

\section{Author details}

'Department of Chemical Pathology, University of Zimbabwe, College of Health Sciences, P.O. Box A178, Avondale, Harare, Zimbabwe. ${ }^{2}$ Department of Immunology, University of Zimbabwe, College of Health Sciences, P.O. Box A178, Avondale, Harare, Zimbabwe. ${ }^{3}$ Research Support Centre, University of Zimbabwe, College of Health Sciences, P.O. Box A178, Avondale, Harare, Zimbabwe. ${ }^{4}$ Department of Obstetrics and Gynaecology, University of Zimbabwe, College of Health Sciences, P.O. Box A178, Avondale, Harare, Zimbabwe.

Received: 20 July 2016 Accepted: 3 February 2017 Published online: 13 February 2017

\section{References}

1. WHO. Global Tuberculosis Report 2014. Geneva: World Health Organization; 2014. http://www.who.int/tb/publications/global_report/en/. Accessed 21 Dec 2014

2. Sita-Lumsden A, Lapthorn G, Swaminathan R, Milburn HJ. Reactivation of tuberculosis and vitamin D deficiency: the contribution of diet and exposure to sunlight. Thorax. 2007;62:1003-7.

3. Leandro ACCS, Rocha MA, Cardoso CSA, Bonecini-Almeida MG. Genetic polymorphisms in vitamin D receptor, vitamin D-binding protein, Toll-like receptor 2 , nitric oxide synthase 2 , and interferon- $-\gamma$ genes and its association with susceptibility to tuberculosis. Braz J Med Biol Res. 2009;42: $312-22$

4. Nava-Aguilera E, Andersson N, Harris E, Mitchell S, Hamel C, Shea B, et al. Risk factors associated with recent transmission of tuberculosis: systematic review and meta-analysis [Review article]. Int J Tuberc Lung Dis. 2009:13:17-26.

5. Wu G, Zhao M, Gu X, Yao Y, Liu H, Song Y. The effect of P2X7 receptor 1513 polymorphism on susceptibility to tuberculosis: A meta-analysis. Infect Genet Evol. 2014;24:82-91.

6. Martineau AR, Wilkinson KA, Newton SM, Floto RA, Norman AW, Skolimowska K, et al. IFN- $\gamma$-and TNF-independent vitamin D-inducible human suppression of mycobacteria: the role of cathelicidin LL-37. J Immunol. 2007:178:7190-8.

7. Liu PT, Stenger S, Tang DH, Modlin RL. Cutting edge: vitamin D-mediated human antimicrobial activity against Mycobacterium tuberculosis is dependent on the induction of cathelicidin. J Immunol. 2007;179:2060-3.

8. Gombart AF, Borregaard N, Koeffler HP. Human cathelicidin antimicrobial peptide (CAMP) gene is a direct target of the vitamin $D$ receptor and is strongly up-regulated in myeloid cells by 1, 25-dihydroxyvitamin D3. FASEB J. 2005;19:1067-77.

9. Ramanathan B, Davis EG, Ross CR, Blecha F. Cathelicidins: microbicidal activity, mechanisms of action, and roles in innate immunity. Microb Infect. 2002:4:361-72

10. Campbell GR, Spector SA. Vitamin D inhibits human immunodeficiency virus type 1 and Mycobacterium tuberculosis infection in macrophages through the induction of autophagy. PLoS Pathog. 2012;8(5):e1002689.

11. Zijenah LS, Kadzirange G, Bandason T, Chipiti MM, Gwambiwa B, Makoga F, et al. Comparative performance characteristics of the urine lipoarabinomannan strip test and sputum smear microscopy in hospitalized
HIV-infected patients with suspected tuberculosis in Harare, Zimbabwe. BMC Infect Dis. 2016:16:1.

12. Peter JG, Zijenah LS, Chanda D, Clowes P, Lesosky M, Gina P, et al. Effect on mortality of point-of-care, urine-based lipoarabinomannan testing to guide tuberculosis treatment initiation in HIV-positive hospital inpatients: a pragmatic, parallel-group, multicountry, open-label, randomised controlled trial. Lancet. 2016;387:1187-97.

13. Boehme CC, Nabeta P, Hillemann D, et al. Rapid molecular detection of tuberculosis and rifampin resistance. N Engl J Med. 2010;363:1005-15.

14. SD Standard Diagnostics. Available: http://www.standardia.com/en/home/ product/rapid/infectious-disease/TB_Ag_MPT64.htm. Accessed 27 Jan 2015.

15. Jones G. Pharmacokinetics of vitamin D toxicity. Am J Clin Nutr. 2008;88: $5825-6$.

16. Conesa-Botella A, Goovaerts O, Massinga-Loembe M, Worodria W, Mazakpwe $\mathrm{D}$, Luzinda $\mathrm{K}$, et al. Low prevalence of vitamin $\mathrm{D}$ deficiency in Ugandan HIV-infected patients with and without tuberculosis. Int J Tuberc Lung Dis. 2012;16:1517-21.

17. Holick MF, Vitamin D. Deficiency. N Engl J Med. 2007;357:266-81.

18. Dawson-Hughes B, Heaney RP, Holick MF, Lips P, Meunier PJ, Vieth R. Estimates of optimal vitamin D status. Osteoporos Int. 2005;16:713-6.

19. Wejse C, Olesen R, Rabna P, Kaestel P, Gustafson P, Aaby P, et al. Serum 25hydroxyvitamin $D$ in a West African population of tuberculosis patients and unmatched healthy controls. Am J Clin Nutr. 2007;86:1376-83.

20. Melamed ML, Michos ED, Post W, Astor B. 25-hydroxyvitamin D levels and the risk of mortality in the general population. Arch Intern Med. 2008;168:1629-37.

21. Zittermann A, Schleithoff SS, Frisch S, Götting C, Kuhn J, Koertke H, et al. Circulating calcitriol concentrations and total mortality. Clin Chem. 2009;55: 1163-70.

22. Martineau AR, Nhamoyebonde S, Oni T, Rangaka MX, Marais S, Bangani N, et al. Reciprocal seasonal variation in vitamin D status and tuberculosis notifications in Cape Town, South Africa. Proc Natl Acad Sci. 2011:108:19013-7.

23. Wilkinson RJ, Llewelyn M, Toossi Z, Patel P, Pasvol G, Lalvani A, et al. Influence of vitamin D deficiency and vitamin D receptor polymorphisms on tuberculosis among Gujarati Asians in west London: a case-control study. Lancet. 2000;355:618-21.

24. Nielsen NO, Skifte T, Andersson M, Wohlfahrt J, Søborg B, Koch A, et al. Both high and low serum vitamin D concentrations are associated with tuberculosis: a case control study in Greenland. Br J Nutr. 2010;104:1487-91.

25. Friis H, Range N, Changalucha J, PrayGod G, Jeremiah K, Faurholt-Jepsen D, et al. Vitamin D status among pulmonary TB patients and non-TB controls: A cross-sectional study from Mwanza, Tanzania. PLoS One. 2013;8:e81142.

26. Engelsen $\mathrm{O}$. The relationship between ultraviolet radiation exposure and vitamin D status. Nutrients. 2010;2:482-95.

27. Herzog H. History of tuberculosis. Respiration. 1998;65:5-15.

28. Mutt SJ, Hyppönen E, Saarnio J, Järvelin MR, Herzig KH. Vitamin D and adipose tissue-more than storage. Front Physiol. 2014;5(228):1-9.

29. Davies PD, Church HA, Brown RC, Woodhead JS. Raised serum calcium in tuberculosis patients in Africa. Eur J Respir Dis. 1987;71:341-4.

30. Mastala Y, Nyangulu P, Banda RV, Mhemedi B, White SA, Allain TJ. Vitamin D deficiency in medical patients at a central hospital in Malawi: a comparison with TB patients from a previous study. PLoS One. 2013;8:e59017.

31. Davies PDO, Brown RC, Woodhead JS. Serum concentrations of vitamin D metabolites in untreated tuberculosis. Thorax 1985:40:187-90.

32. Grange JM, Davies PDO, Brown RC, Woodhead JS, Kardjito T. A study of vitamin D levels in Indonesian patients with untreated pulmonary tuberculosis. Tubercle. 1985;66:187-91.

33. Chan TY, Poon P, Pang J, Swaminathan $\mathrm{R}$, Chan $\mathrm{CH}$, Nisar M, et al. A study of calcium and vitamin $D$ metabolism in Chinese patients with pulmonary tuberculosis. J Trop Med Hyg. 1994:97:26-30.

34. Hong JY, Kim SY, Chung KS, Kim EY, Jung JY, Park MS, et al. Association between vitamin $D$ deficiency and tuberculosis in a Korean population. Int J Tuberc Lung Dis. 2014;18:73-8.

35. Sarin P, Duffy J, Mughal Z, Hedayat E, Manaseki-Holland S. Vitamin D and tuberculosis: review and association in three rural provinces of Afghanistan. Int J Tuberc Lung Dis. 2016;20:383-8.

36. Ho-Pham LT, Nguyen ND, Nguyen TT, Nguyen DH, Bui PK, Nguyen VN, et al. Association between vitamin D insufficiency and tuberculosis in a Vietnamese population. BMC Infect Dis. 2010;10:306.

37. Mao X, Zheng H, Liu Z, Wu Y, Na R, Wang C, et al. Analysis of $25(\mathrm{OH}) \mathrm{D}$ serum concentrations of hospitalized elderly patients in the shanghai area. PLoS One. 2014;9:e90729. 